\title{
The In-Terrorem Value of Science: Bisphenol-A Litigation and an Empirical Assessment of Science as a Collective Litigation Tool
}

\author{
Suman Kakar ${ }^{1}$, Sanjeev Sirpal ${ }^{2}$ \\ ${ }^{1}$ School of Criminal Justice, Honors College, Florida International University, Miami, USA; ${ }^{2}$ College of Law, Florida International \\ University, Miami, USA. \\ Email: kakars@fiu.edu, ssirp001@fiu.edu
}

Received June $10^{\text {th }}$, 2010; revised February $18^{\text {th }}$, 2011; accepted March $24^{\text {th }}, 2011$.

\begin{abstract}
This paper examines the role that science plays as a tool in collective litigation to substantiate claims. Scientific data and expert testimony are often included to buttress a claim and the admissibility of such evidence is often a consequence of the extant evidentiary rules and their application. The article will focus on the multidistrict litigation concerning Bisphenol-A ("BPA") as a case study of the phenomena of scientific tailoring of evidence and its admissibility. $B P A$ is a compound included in the synthesis of plastics and is found in food containers, plastic bottles, and epoxy-based coatings used to avert the rusting process of food containers. There is a negligible amount of BPA in several food and beverage products. Several countries along with the US Food and Drug Administration (FDA) and Environmental Protection Agency (EPA) have marshaled scientific studies that demonstrate the lack of any definable negative health effect attributable to an exposure to trace amounts of BPA. Notwithstanding the conclusions of these scientific inquiries, opponents have asserted that BPA exposure results in an alteration of embryonic hormone levels, thereby impacting their development and later reproductive function. This article will address these issues in addition to the salient question of what role science plays as a tool for collective litigation.
\end{abstract}

Keywords: Collective Litigation, Scientific Evidence, Bisphenol-A, BPA, Expert Testimony

\section{Introduction}

Bisphenol-A ("BPA") is a compound included in the synthesis of plastics and is found in food containers, plastic bottles, and epoxy-based coatings used to avert the rusting process of food containers. There is a negligible amount of BPA in several food and beverage products. Several countries along with the US Food and Drug Administration (FDA) and Environmental Protection Agency (EPA) have marshaled scientific studies that demonstrate the lack of any definable negative health effect attributable to an exposure to trace amounts of BPA. Notwithstanding the conclusions of these scientific inquiries, opponents have asserted that the negative consequences of BPA exposure manifest as an alteration of an embryo's hormone levels which thereby impact their development and later reproductive function.

The questions presented thus far in the litigation concerning $\mathrm{BPA}^{1}$ surround 1 ) the issue of primary jurisdiction and 2) federal preemption. Specifically, the court considered the defense's argument, i.e., the court lacks primary jurisdiction as such lies with the FDA exclusively on the BPA issue. The defendants' argument was presented as a basis for dismissal of the lawsuit. The court denied the defense's motion, and reasoned that there is a distinction in the charge of the court at that juncture and the regulatory latitude of the FDA as it relates to BPA. The court held that, concerning the defendants' federal preemption argument, the question was addressed by the Supreme Court's ruling ${ }^{2}$ where it was held that states could create and implement further regulations above and beyond a federal regulatory "floor". This article will address these issues in addition to the salient question of what role science plays as a tool for collective litigation.

WHAT IS BPA?

\footnotetext{
${ }^{1}$ In re Bisphenol-A (BPA) Polycarbonate Plastic Products Liability Litigation, MDL No. 1967, Slip Op. 1 (W.D. Mo. Nov. 9, 2009).

${ }^{2}$ Wyeth v. Levine, 129 S. Ct. 1187 (2009).
} 
BPA is an endocrine disruptor found in many consumer products including infant formula cans and bottles. It may be affecting the reproductive and metabolic health of infants and children. While some uncertainty exists about its effects, there is some scientific evidence that BPA is harmful, enough that some countries have banned its usage from infant and children's products. Proponents of a ban on BPA argue that by adopting the precautionary principle, these measures would protect our most vulnerable population from harm as evaluation of BPA's safety continues.

BPA is used as a liner in most tin cans including infant formula cans, and in baby bottles, sippy cups, dental sealants, and bicycle helmets [1]. BPA is not acutely toxic, meaning that poisonous effects do not occur following a single exposure. Instead, BPA is an endocrine disruptor, an agent which acts like a hormone inside the body and interferes with natural physiological processes.

Some data indicates that there may be an effect of low-level BPA exposure on the correct functioning of hormones, especially during early stages of development [2]. Infants are considered a particularly susceptible risk group. In animals, BPA has been linked to various reproductive, neurodevelopmental, and metabolic problems. Epidemiological studies, which focus on health effects in human populations, have found correlations between higher levels of BPA and more of these physiological effects, as well as higher levels of heart disease. However, these studies are highly contested by plastics industry leaders.

Many countries are currently evaluating their response to the regulation of BPA. Canada has banned BPA for various products including baby bottles. In Japan, manufacturers have instituted a voluntary reduction on BPA's usage in food canisters. Following the voluntary reduction of BPA, Japanese BPA body burdens, the amount of a substance found in each human body [3] have declined as well. To date, America and the European Union (the "EU") currently hold that the use of BPA is acceptable. In addition, despite recent voluntary production of BPAfree plastic bottles in the United States, baby bottles containing BPA continue to be produced internationally.

There is a recent American movement to remove BPA from food and beverage receptacles, and products for infants and children under age three. The U.S. FDA in August 2008 reiterated its intention not to regulate BPA in food and beverage receptacles. In response, in 2009, the states of Minnesota and Connecticut, as well as local governments in Chicago, Illinois and Suffolk County, New York, all instituted local restrictions or bans on the inclusion of BPA as a chemical component of baby bottles, formula cans, or other children's products.
Voluntary efforts have also limited BPA production. In 2008, consumer groups voiced their concerns. Major retailers responded by refusing to stock baby bottles and other drinking containers containing BPA, and some manufacturers began to produce BPA-free alternatives. For instance, the six main corporate producers of baby bottles agreed in March 2009 to a ban on the usage of BPA in infant food sources or containers sold in the United States. Next, a chemical manufacturer of BPA, Sunuco, announced that it would no longer sell its plastic to makers of children's products. However, other manufacturers such as Dow Chemical Company, Bayer, and Hexion Specialty Chemicals continue to market BPA and to use it as a liner in cans of infant formula, in baby food containers, in toddler sippy cups, and in many other infant and children's products.

In addition to voluntary efforts at BPA reduction, there have been legislative efforts to achieve the same goal. In March 2009, the U.S. House of Representatives introduced a bill barring the inclusion of BPA in food and beverage containers, and in July 2009, the FDA announced its intention to reconsider its BPA decision.

Proponents of a BPA ban point to the limited scientific data showing its deleterious effects and argue that a comprehensive national plan for control of BPA would be the most effective way to address these problems, because voluntary efforts cannot be monitored or enforced. How strong is such scientific evidence and should it be legally admissible to buttress a collective tort claim?

\section{The Evolution of Legal Admissibility of Scientific Evidence}

This subsection traces the requirements for legal admissibility of scientific evidence, starting with Federal Rule of Evidence 702, and then a discussion of the Frye and Daubert evidentiary standards. This analysis is subsequently applied to the evidence sought to be admitted in In re BPA Litigation. The extent of evidentiary support necessary to corroborate the admissibility of such evidence is reviewed, along with a review of the available published research. It is argued that the experimental outcomes that would establish the health consequences of BPA and the standards on which conclusions are based are lacking. Accordingly, it is argued that the available research on the deleterious health consequences of BPA fail to meet judicial evidentiary standards for the admissibility of scientific evidence.

FEDERAL RULE OF EVIDENCE 702

Federal Rule of Evidence 702 states that:

If scientific, technical, or other specialized knowledge will assist the trier of fact to understand the evidence or to determine a fact in issue, a witness qualified as an ex- 
pert by knowledge, skill, experience, training, or education, may testify thereto in the form of an opinion or otherwise, if (1) the testimony is based upon sufficient facts or data, (2) the testimony is the product of reliable principles and methods, and (3) the witness has applied the principles and methods reliably to the facts of the case.

A dissection of FRE 702 reveals a test for the admission of an expert's opinion or scientific evidence: 1) Does the expert's opinion relate to a matter of scientific, technical or specialized knowledge?; and 2) Will the expert's testimony be helpful to the trier of fact in determining a fact at issue in the case? To be rendered admissible, "scientific knowledge" must be more than a mere belief; it must be fact or theory rooted in methods or procedures of science.

Frye and Daubert were two decisions that subsequently informed the courts' application of Rule 702 in rulings on the admissibility of scientific evidence.

\subsection{The Frye and Daubert Standards}

Courts have historically (from the beginning of the fourteenth century) circumscribed the admissibility of hearsay evidence, specifically lay opinion testimony. Notwithstanding the restricted admissibility of opinion testimony, it was generally rendered admissible where such evidence was determined to be something other than common sense and the opinion is rather predicated on the witness's independent and objective qualifications as an expert. Such expertise is generally gained through particular training, knowledge, skill or experience in the relevant subject area. This has molded the courts' rulings on admission of scientific opinion testimony.

The "Frye Rule," i.e., scientific evidence is admissible only if it evinces "general acceptance" within the specific area of study, delineated the initial substantive constraints on the admissibility of expert testimony/evidence. The Frye rule remained the most broadly adopted and followed rule regulating the admission of scientific expert testimony and corresponding expert scientific evidence until Daubert.

"Before its admission as evidence, scientific evidence must have gained general acceptance in the relevant scientific community, evinced by reliability and acceptance by disinterested members of the scientific community". Subsequent to Frye, there was a change in the admissibility of scientific evidence in the federal courts. This change in legal doctrine occurred secondary to the United States Supreme Court's landmark decision in Daubert v. Merrell Dow Pharmaceuticals, Inc.

The Daubert Court held that Rule 702 of the Federal Rules of Evidence, not Frye, was controlling as the appropriate standard for determining admissibility of expert testimony as to scientific evidence in federal courts.

The Daubert Court provided several factors pertinent to the determination of the admissibility of expert "scientific knowledge"-1) whether the evidence is based on a testable theory or technique; 2) whether the theory or technique has been subjected to peer review and publication; 3) the known or potential error rate of the theory or technique; and, 4) general acceptance of the theory or technique within the scientific community. These factors are not all-inclusive and do not purport to be exhaustive. Rather, they were intended as a guide in the application of the "flexible" "inquiry envisioned by Rule 702."

In a post-Daubert judiciary, federal court judges play a "gatekeeper" role concerning the admissibility of scientific evidence. The trial judge is charged with the dual tasks of 1) determining the qualifications of the expert and 2) determining "whether the expert's methodology is reliable." Since these are considered "preliminary rulings" within the Federal Rules of Evidence, in a Daubert hearing, the trial judge applies Rule 104(a) to assess the qualifications of the expert witness and determine whether the specific rationale underlying the expert's scientific testimony is grounded in sound science and can be applied appropriately to the facts at issue. In Daubert, Justice Blackmun explicated the basis of Rule 702's deviation from the strictures of the Frye test:

Nothing in the text of this Rule establishes "general acceptance" as an absolute prerequisite to admissibility... The drafting history makes no mention of Frye, and a rigid "general acceptance" requirement would be at odds with the "liberal thrust" of the Federal Rules and their "general approach of relaxing the traditional barriers to 'opinion' testimony.”

Subsequent to Daubert, several states followed the federal judiciary's model and disposed of the Frye rule and in its place, followed Daubert's newer, arguably less stringent approach to the admissibility of expert testimony/scientific evidence. Widespread ideological differences soon erupted among courts and commentators as to the scope of Daubert's application-whether it was applicable to expert testimony in general, or scientific expert testimony in particular. Similarly, broad confusion and disagreement permeated the discussion of whether Daubert was applicable to "experience-based testimony" in contrast to research-backed testimony.

The Supreme Court sought to address these concerns in Kumho, a case arising due to a car crash which was allegedly caused by the implosion of a tire. In that case, the plaintiffs argued that the tire defect occurred secondary to a latent manufacturing defect in the tire itself. Expert testimony was proffered to buttress their stance. The defendants attempted to suppress the admissibility of 
plaintiff expert's testimony based on grounds of Daubert. The trial court rendered the plaintiff expert's testimony inadmissible on grounds of Daubert and accordingly granted summary judgment for defendants. On appeal, the plaintiffs adopted a stance that Daubert was inapplicable to "experience-based technical opinions". The Supreme Court did not accept such reasoning and instead found that the trial court's "gatekeeping function under Daubert applied not only to scientific testimony but to all expert testimony based on scientific, technical or other specialized knowledge". Examining the language of FRE 702, the Court stated that the rule does not distinguish "scientific," "technical" and "other specialized" knowledge. Hence, Kumho states that the federal courts "gatekeeping" function pursuant to Daubert is applicable to all testimony offered pursuant to rule 702, even "experiential technical testimony”.

This ruling may prove to be potentially prejudicial to plaintiffs because of the broad latitude afforded trial judges in making the determination of the reliability of the proffered scientific testimony, but also, the means, rationale, and methodology employed to determine reliability. The Court's holding in Kumho clarifies that evidentiary rules evidence afford the trial court judge with the same discretion when it reaches a decision on how to determine reliability as the judge would have in making the final reliability determination.

The role of the court as a gate keeper is supported by a two-fold rationale [4]: 1) it is imperative that an expert utilize the "same level of intellectual rigor in the courtroom that characterizes the practice of an expert in the relevant field," regardless of whether the professional opinion is predicated on scientific studies or personal experience and that 2) upon a challenge to the factual basis of the opinion, methodologies, or their specific application, the trial judge is charged with determining the reliability of the testimony in terms of its scientific and/or experiential underpinnings . Furthermore, the specific Daubert factor analysis is triggered in particular cases where the lower court/tribunal reaches the conclusion that "they are reasonable measures of the reliability of expert testimony."

The trial court's charge is not only to determine the reliability or usefulness of the methodology applied, but, more importantly, to make such a determination in accordance to the specific factors and issues of the case. The abuse of discretion standard is the appropriate standard on appellate review of the lower court's bipartite decision of 1) the reliability of the testimony and 2) "how to determine whether it is reliable."

The two aspects of the Daubert requirements, reliability and general acceptance, are holdovers from the Frye test. Among the Daubert factors, the initial three are essentially a greater in-depth analysis of reliability factors and how that determination was reached, while the final is a holdover of the notion of general acceptance from the Frye test. "Near unanimity is not required to establish acceptance, but some measure of approval from the scientific community must be shown before use of scientific evidence.”

\section{The BPA Case's Influence on the Standard of Evidence}

The origins of litigation surrounding the usage of Bisphenol A are found in the 2008 formation of the Bisphenol-A/Phthalates Proposed Litigation Group by the American Association of Justice (“AAJ"). The class action lawsuit [5] was initiated in a Missouri federal district court with the assistance of the AAJ. That suit was filed against numerous baby bottles and baby formula corporate producers concerning the inclusion of BPA in baby bottles, food containers, and as an adhesive in baby formula cans.

The class action plaintiff consumers' legal argument was that the usage of BPA as a chemical component of baby products amounted to a failure of disclosure of a material fact, i.e., pursuant to applicable state consumer protection laws, the manufacturer was legally obliged to make such a disclosure. Notably, the plaintiffs are not asserting any personal injury secondary to exposure to BPA. Rather, plaintiffs are arguing consumer fraud, misrepresentation, breach of warranties, and economic injury. The main assertion is that had they had knowledge of the presence of BPA, they would not have purchased the products at hand.

The federal district court, in response to the number of putative consumer fraud class actions surrounding BPA convened the Joint Panel on Multidistrict Litigation, which created an MDL [5]. About forty-eight matters are merged and are currently before the Western District of Missouri $^{3}$. The court issued a recent ruling on the Defendants' motions to dismiss.

In its slip opinion, the court addressed the defense's motions to dismiss on the dual bases of primary jurisdiction and federal preemption ${ }^{4}$. The court then expounded on the regulatory underpinnings of BPA. The FDA has created regulations that specifically delineate the healthy and sanctioned use of specific plastic derivatives that are deemed approved "food additives" under the FDA [8], i.e., resinous and polymeric coatings. The court reached a determination that there is a reasonable inference to draw

${ }^{3}$ Frye v United States, 54 US App DC 46; 293 F 1013 (1923).

${ }^{4} 509$ US 579; 113 S Ct 2786; 125 L Ed 2d 469 (1993). 
that the FDA has concluded the safety of food additives containing BPA without labeling since the FDA is obliged to use such labeling if it were required for health and/or safety reasons ${ }^{5}$.

The court denied the defense's primary jurisdiction argument, i.e., that the FDA has primary jurisdiction on the BPA issue, rendering dismissal of plaintiff's lawsuit as the remedy sought by the defense. The court drew an interesting, albeit presumptively spurious distinction between the charge of the court and the regulatory authority of the FDA:

"However, the ultimate issues in these cases are whether defendants failed to disclose material facts to Plaintiffs and whether Defendants breached the implied warranty of merchantability through the sale of products containing $\mathrm{BPA}^{6}$. The FDA cannot resolve these questions, and the FDA's determination that BPA is 'safe' is not determinative of any of those issues."

The court next examined the defendants' federal preemption argument ${ }^{7}$. The court declined to adopt the defendants' reasoning relying on a recent Supreme Court decision finding conflict preemption in a case where a particular state law claim would essentially effectuate a denial of applicable federal law. Rather, the court found dispositive another Supreme Court opinion ${ }^{8}$ wherein the court held that "federal regulation represented a floor above which states could impose additional requirements",

The court concluded otherwise concerning the infant formula defendants. These defendants did not couch their preemption argument in terms of 'conflict preemption', but instead on the "express preemption provisions involving the FDCA's misbranding provisions and accompanying regulations" ${ }^{\prime 10}$. These defendants referenced the "FDA's determination that epoxy resins are exempt from disclosure under the FDA's regulation governing incidental additives" ${ }^{\prime 1}$. Given that the FDCA has issued an express prohibition on state institution of labeling of food distinguishable from federal requirements, the Court held that "the plaintiffs' claims would embody a disclosure requirement that is the exact opposite of the nondisclosure of incidental additives that the FDA's regulation

\footnotetext{
${ }^{5}$ Daubert, 509 U.S. at 579.

${ }^{6}$ Kumho Tire v. Carmichael, 119 S.Ct. 1167 (1999).

${ }^{7}$ Kumho Tire, 119 S.Ct. 1167 (1999).

${ }^{8}$ Daubert at 593-594.

${ }^{9}$ Daubert offers the following factors as key points of inquiry in establishing acceptance: (1) testing of the hypothesis, (2) peer review of the hypothesis or technique, (3) error rates of and standards for the technique, and (4) the degree of acceptance within the relevant scientific community.

${ }^{10}$ Daubert at 593-594.

${ }^{11}$ In re: Bisphenol A (BPA) Polycarbonate, 571 F. Supp. 2d 1374 (J.P.M.L. 2008)
}

provides” ${ }^{12}$.

The class action plaintiffs argued that they should have been classified as under a "safety exemption" to the express preemption provision of the FDCA. The court, however, deferred in judgment to its earlier ruling, finding that the FDA had concluded that it is safe to use BPA as an incidental additive. Accordingly, the court found that "the claims against the infant formula defendants are expressly preempted, but the claims against the baby bottle defendants are not" ${ }^{\text {13 }}$.

In a second slip opinion, the court scrutinized the "motions to dismiss the individual counts of the complaint: [3] violation of state consumer fraud laws, breach of express warranties, breach of implied warranties, intentional misrepresentation, negligent misrepresentation, and unjust enrichment" [4].

The court first held that "the plaintiffs failed to plead with the particularity required by Federal Rules of Civil Procedure 8 and 9(b) the express statements that formed the basis of their fraud, misrepresentation, and breach of express warranty claims", noting that "platitudes about a particular Defendant's commitment to safety and quality or general allegations about a particular Defendant's marketing and advertising strategy were insufficient to state a claim for misrepresentation"14. Analogously, the court noted that the lack of specificity in pleading is irreconcilable with the absolute requirement that "a plaintiff pleading a breach of express warranty claim plead that it was part of the basis of the bargain.”

Notwithstanding this, the court denied Defendant's motion to dismiss the consumer fraud and misrepresentation claims (based on "the failure to disclose the presence of BPA in the products"), reasoning that "all jurisdictions surveyed create a duty to disclose material facts that are more readily known by one side of the transaction."15 However, imposing a duty of disclosure is not predicated solely on "superior" knowledge, but rather what is deemed "material". Interestingly, the imposition of a "superior" knowledge disclosure requirement would result in the unmanageable and impractical disclosure of each constituent of a final product. The court will likely have to garner evidentiary support to sustain its finding since the FDA already has reached a conclusion on the safety of negligible amounts of BPA in bottles or formula. Hence, the presence of BPA cannot be "material as a matter of law", especially since its presence is readily ascertainable from public sources.

\footnotetext{
${ }^{12}$ In re Bisphenol-A (BPA) Polycarbonate Plastic Products Liability Litigation, MDL No. 1967, Slip Op. 1 (W.D. Mo. Nov. 9, 2009).

${ }^{13}$ In re Bisphenol-A (BPA) Polycarbonate Plastic Products Liability Litigation, MDL No. 1967, Slip Op. 1 (W.D. Mo. Nov. 9, 2009).

${ }^{14}$ Geier v. American Honda Motor Co., 529 U.S. 861 (2000).

${ }^{15}$ Wyeth v. Levine, 129 S. Ct. 1187 (2009).
} 
The court dismissed the "claims for breach of the implied warranty of fitness for a particular purpose because plaintiffs failed to identify a purpose other than the typical one for the subject products” ${ }^{\prime \prime}$. However, the court did not thoroughly scrutinize the state unjust enrichment law to even reach the merits on the Defendants' motion concerning this count. Additionally, the court had an uncanny interpretation of the "unmanifested defect" argument [5]. Defendants argued that "without a plaintiff having actually experienced a physical harm from the product, he suffered no cognizable harm whatsoever" [5]. The court disagreed, suggesting:

"The buyer has been damaged regardless of whether he replaces or disposes of the product because, either way, he has paid the seller for a product that he would not have purchased had he known that the poison was present, and has received no use from the product. The poison may not injure him, but the condition complained of-poison's presence-is known to exist. Similarly, the Plaintiffs in this category purchased a product they allege they would not have purchased had they known the true facts.”

Based on this analysis, the court held that "plaintiffs who had not used their products still had a claim", while "those who had used their products had obtained the full value of their products and had not suffered any damage." ${ }^{17}$. The case is currently proceeding through discovery.

The court's conclusions are not easily reconcilable with the court's acknowledgement of the "safety" of food additives including BPA. "A legal claim premised on know[ledge] that the poison was present is wholly inconsistent with the FDA's safety determination that BPA is not a 'poison' at all". Presumably, ongoing litigation of In re: Bisphenol A will involve the issue of BPA science and the complexity involved in solidifying general and specific causation.

These concerns evoke the need for a scrutiny of the scientific underpinnings of the deleterious consequences of BPA.

\subsection{Scientific Studies Concerning BPA}

The health effects of BPA have been studied extensively for years. The widespread focus on BPA largely is due to the inclusion of BPA in many baby products. The limited research showing that BPA may be considered an endocrine disruptor, i.e., that it may "interfere with normal development of the reproductive system and other hor-

\footnotetext{
${ }^{16}$ In re Bisphenol-A (BPA) Polycarbonate Plastic Products Liability Litigation, MDL No. 1967, Slip Op. 1 (W.D. Mo. Nov. 9, 2009).

${ }^{17}$ In See In re Bisphenol-A (BPA) Polycarbonate Plastic Products Liability Litigation, MDL No. 1967, Slip Op. 2 (W.D. Mo. Nov. 9, 2009).
}

monally mediated systems”, has been another fact sparking interest in $\mathrm{BPA}^{18}$.

BPA is consumed predominantly through oral ingestion. Specifically, polycarbonate bottles (i.e., plastic bottles) can diffuse very small concentrations of BPA into the liquid contained therein. Further, BPA can be diffused from the inner lining of metallic and plastic food and drink receptacles into the corresponding food and liquids contained therein [7]. Most domestic producers of canned baby formula use epoxy linings that include BPA, and which can diffuse BPA into the infant formula, especially upon heating. "Microwaving plastic containers to heat food is another possible exposure pathway, although it is generally recognized that the levels of BPA that could leach from hard plastics is low. Nonetheless, consumer groups recommend avoiding the use of plastic containers to heat food, especially for young children.” [8].

After being ingested, "BPA can bind to estrogen receptors, although its binding affinity is orders of magnitude lower than that of endogenous estrogen”. The main point of contention between supporters of a BPA ban and opponents arises because "evidence that a compound can have a certain effect in the body under certain circumstances is a far cry from establishing that the compound does affect the body at levels likely to be encountered from the typical low-level oral or dermal ingestion that occurs, for example, through leaching” [8]. As such basic pharmacological principles of dose, duration, and species extrapolation lie at the heart of the debate [8].

\subsection{The Paucity of Published, Independent Scientific Studies Evincing BPA's Negative Health Consequences}

BPA's low estrogenic potency, combined with the low level of human exposure, has often been understood as indicative of the lack of risk to humans from BPA exposure. This lack of evidence evincing the negative health consequences of BPA are supported by data from a recent meta-analysis of "risks associated with low-level exposure to BPA" conducted by the FDA (2008) and experts at the Harvard Center for Risk Analysis (2004). There, the authors found "no consistent evidence for BPA-related health effects, supporting the safety of current low levels of human exposure to BPA" [7].

Interestingly, in 2008, the National Toxicology Program ("NTP") at the National Institutes of Health ("NIH") reached an opposite result, i.e., concluded that the inclu-

\footnotetext{
${ }^{18}$ Recent evidence from the National Health and Nutrition Examination Survey ("NHANES III") conducted by the Centers for Disease Control and Prevention ("CDC") found detectable levels of BPA in most people six years and older who were tested.
} 
sion of BPA may be concerning. In order to gauge the admissibility of seemingly contradictory evidence, it is important to apply the relevant evidentiary standards. Notably, NTP reports are not peer-reviewed publications, and are not even quantitative assessments. Rather, they assess the negative consequences and toxicity of a substance as it relates to five "levels of concern." "These levels range from "serious concern" (the substance causes reproductive/developmental effects in humans or in laboratory animals under typical human exposure conditions) to "negligible concern" [8] (there is good evidence that the substance under evaluation is not a reproductive or developmental toxicant)". The NTP report concluded that "there was 'some concern' that BPA exposure in fetuses and infants could possibly affect brain and prostate health". Notably, for all other facets of human BPA exposure, the NTP found only "minimal" or "negligible concern." A finding of "some concern" by the NTP is indicative of the need for more research. Indeed, the NTP studies concede that there is only very limited evidence of the negative effects of BPA on development. Hence, the NTP studies themselves indicate the necessity for more research to better understand the role of BPA and its implications for human health. Notwithstanding the limitations of the NTP report, its characterization by the media led to public concern and a deluge of regulatory and litigation activity ${ }^{19}$.

Echoing the results of the NTP report, the FDA on January 15, 2010, issued an official update, presumably on tremendous political pressure, expressing "some concern about the potential effects of BPA on the brain, behavior and prostate gland of fetuses, infants and children." However, the FDA report noted that "there was no evidence that BPA was unsafe. The Department of Health and Human Services - through the CDC, NIH, and the FDA-is investing more than \$30 million in new health studies in both animals and humans to better determine and evaluate the potential health effects of BPA exposure. These studies, involving rodents and nonhuman primates, will focus on the metabolic impact of oral versus intravenously administered BPA, the effect of oral BPA ingestion on the prostate and mammary glands, and at what, if any, dose point BPA may negatively affect behavioral and neuroanatomical development". The results of these studies are expected to be released in approximately two years [8].

Judging from the media response of the NTP report, it is likely that a similar response will be evoked upon the release of the FDA report on this research. Awaiting these results, proponent of stricter regulation of BPA will

${ }^{19}$ Recently, a major independently-funded study by the EPA failed to find evidence of low-dose effects from BPA. continue to buttress their claim on studies that likely do not meet the applicable evidentiary standards for admissibility, e.g., a recent "Consumer Reports article advocating the avoidance of all canned foods due to the presence of leached BPA". In parallel, such proponents will likely dismiss empirical research demonstrating the safety of low-level BPA exposure as the product of industry bias.

\section{Conclusions}

Applying the evidentiary standards for admissibility to the BPA case, it is not difficult to reach the conclusion that the available evidence of BPA's negative health effects does not reach the applicable threshold for admissibility. The available evidence demonstrates that BPA is ubiquitous; it is found in negligible amounts in several food and beverage products that humans regularly consume. Further, the U.S. FDA and EPA, Canada, the European Union, Germany, Japan, Norway, Australia, and New Zealand, have all released the results of empirical studies or meta-analyses indicating the lack of any known health risk from low-dose exposure to BPA [8].

Notwithstanding this evidence and the notable paucity of peer-reviewed research supporting a contrary finding, proponents of BPA regulation, class action plaintiffs, and some scientists have stoked the political fire, lodging attacks against the FDA for its findings and promoting strict regulation and prohibitions of the inclusion of BPA in consumer products. Such proponents buttress their claim on shaky science, the specter of "small concern" that much higher than normal dose exposure to BPA can affect embryos in utero and small children, affecting embryological and later reproductive function. Based on this calculus, BPA litigation is a prime case study demonstrating the notion that science can, and is, being used as a tool of collective litigation.

\section{REFERENCES}

[1] National Toxicology Program, U.S. Department of Health \& Human Services, NTP-CERHR Expert Panel Report for Bisphenol A, 26 November 2007.

http://cerhr.niehs.nih.gov/chemicals/bisphenol/BPAFinal EPVF112607.pdf [hereinafter NTP Expert Panel Report] (Description of NTP and Significance of This Report Infra Section IIIA).

[2] Environmental Working Group, "Bisphenol A: Toxic Plastics Chemical in Canned Food: A Survey of Bisphenol A in U.S. Canned Foods,” 2007.

http://www.ewg.org/book/export/html/20928 [hereinafter EWG Report].

[3] U.S. Agency for Toxic Substance \& Disease Registry, "Glossary of Terms." 2009

http://www.atsdr.cdc.gov/glossary.html [hereinafter ATS 
DR Glossary] (Defining “Body Burden”).

[4] “The Expert and Daubert,” Mac News Letters, Vol. 1996. http://www.mac-experts.com/macnewsletters/spring96/Da ubert.htm

[5] P. Lee, "The Daubert Case and Expert Opinion,” Translating Evidence into Practice 1997 Conference Summary-Session B: Scientific Evidence and the Courts. http://www.ahcpr.gov/clinic/trip1997/trip2.htm

[6] "Are Plastic Products Safe? An Overview of the Science.”

http://getbetterhealth.com/are-plastic-products-safe-an-o verview-of-the-science/2009.12.01
[7] "Science Suppressed: How America Became Obsessed with BPA."

http://stats.org/stories/2009/science_suppressed_BPA_int ro_jun12_09.html

[8] "Update on Bisphenol A for Use in Food Contact Applications,” U.S. Food and Drug Administration, January 2010. http://www.fda.gov/downloads/NewsEvents/PublicHealth Focus/UCM197778.pdf

[9] “Concern over Canned Foods." http://www.consumerreports.org/cro/magazine-archive/de cember-2009/food/bpa/overview/bisphenol-a-ov.htm. 